\title{
Viviendo en la escasez: el territorio como objeto de transacción para la sobrevivencia
}

\section{Living with scarcity: the territory as a transaction object for survival}

\author{
María Fernanda Paz-Salinas*
}

\begin{abstract}
In this paper we show why under poverty conditions it is not possible to generate or direct a sustainable management of resources and territories. On the contrary, with the lack of strong local institutions and without a State to guarantee the satisfaction of elementary needs, together with the presence of cultural identities and the sense of belonging and territoriality of the population we witness conditions that lead to the deterioration of communal resources and thus greater poverty.
\end{abstract}

Keywords: scarcity, territory, territorial belonging, indigenous community.

\section{Resumen}

El objetivo de este trabajo es mostrar cómo bajo condiciones de pobreza yante la ausencia tanto de instituciones locales fuertes y de un Estado que garantice la satisfacción de las necesidades elementales de la población, la presencia de identidades culturales y el sentido de pertenencia y territorialidad de los habitantes, sustentados en valores compartidos, prácticas e instituciones normativas, no son condiciones suficientes para generar o encauzar procesos sustentables de manejo de recursos y territorios y sí, por el contrario, es posible que ante la vulnerabilidad generada por la escasez, se presenten condiciones que lleven al deterioro de los recursos comunitarios y, por tanto, a una mayor pobreza.

Palabras clave: escasez, territorio, pertenencia territorial, comunidad indígena.

* Universidad Nacional Autónoma de México, México. Correo-e: pazs@servidor. 


\section{Introducción}

En México, como en muchos otros países latinoamericanos, en las últimas décadas hemos sido testigos de interesantes movimientos sociales en defensa de recursos y territorios, que se articulan en torno a fuertes sentidos de pertenencia e identidad y reclaman el respeto y reconocimiento de derechos ancestrales de posesión (Escobar, 1999a, 1999b; Paz, 2005; Rosas, 1997). Las experiencias nos relatan cómo, ante amenazas externas, las poblaciones locales construyen alianzas hacia adentro y hacia afuera para distinguirse y fortalecerse; rediseñan sus marcos institucionales y formulan, desde sus propios parámetros culturales, estrategias innovadoras, tanto técnicas como políticas, para proteger los intereses colectivos locales frente a la voracidad de intereses privados que normalmente están guiados bajo una lógica de mercado.

La mayoría de estos ejemplos refieren a regiones cuyos recursos y/o ubicación son tan valorados por sus poseedores directos, como codiciados por agentes externos; es decir, son recursos y territorios significados de diferente manera, convirtiéndose así en bienes patrimoniales para unos y mercancías para otros. La defensa de estos patrimonios ha llevado a las comunidades que así los conciben, a marcar de manera contundente sus límites hacia el exterior, construyendo de este modo una nueva territorialidad definida no sólo por sus fronteras físicas, sino también simbólicas; y paralelamente, ha generado propuestas de gobierno local y formas de organización societaria vinculadas al manejo de sus bienes colectivos y a proyectos sociopolíticos de largo plazo (Seoane, 2005; Leff, 2005).

Pero, ¿qué sucede en casos dónde priva una situación de escasez? ¿Cuándo no se trata de territorios codiciados por su alta biodiversidad o ubicación? En este trabajo nos interesa mostrar cómo en situaciones de extrema pobreza económica y de recursos naturales, así como de debilidad política, algunas comunidades indígenas con un fuerte sentido de identidad étnica y pertenencia territorial se ven obligadas a usar su territorio, su patrimonio, como objeto de transacción con otras comunidades vecinas para satisfacer ciertas necesidades básicas y también para garantizar la continuidad de su instancia de gobierno de los recursos comunes; gran paradoja esto último ya que el territorio transado se somete a una situación de acceso abierto, lo que por un lado hace obsoleto el gobierno de los bienes comunes y, por el 
otro, coloca a éstos en una situación de amplia vulnerabilidad y deterioro.

El objetivo de nuestro trabajo es mostrar cómo bajo condiciones de escasez y ante la ausencia tanto de instituciones locales fuertes, como de un Estado que garantice la satisfacción de las necesidades elementales de la población (como el abasto de agua potable), la presencia de identidades culturales y el sentido de pertenencia y territorialidad de los habitantes, no son condiciones suficientes para generar o encauzar procesos sustentables de manejo de recursos y territorios y sí, por el contrario, es posible que, ante la vulnerabilidad, se presenten condiciones que lleven al deterioro de los recursos comunitarios y, por tanto, a una mayor pobreza.

Dividimos nuestra exposición en tres apartados. En el primero presentamos la experiencia de la comunidad indígena de Cuentepec, Morelos, la cual, a partir de una serie de convenios y acuerdos intercomunitarios, expone su territorio a procesos de degradación, al tiempo que pierde autonomía sobre el mismo. En la segunda parte de nuestro trabajo mostramos que en la zona de estudio la identidad cultural y el sentido de pertenencia territorial sustentados en valores compartidos, prácticas e instituciones normativas, no deriva necesariamente en acciones de manejo sustentable o procesos de defensa del territorio; en esta sección llamamos la atención sobre el concepto de escasez, en un sentido amplio, para discutir las implicaciones que ésta tiene en la formulación de propuestas alternativas de manejo de recursos desde el ámbito local. Por último, en el tercer apartado, hacemos algunas reflexiones sobre ciertos aspectos sociales, económicos, políticos y culturales que, al conjugarse, colocan a los territorios y sus habitantes en condiciones de franca vulnerabilidad.

La información que aquí presentamos para documentar el estudio de caso fue recabada en trabajo de campo en el pueblo de Cuentepec, Morelos, donde se levantó un censo de hogares en el año 2004 y se hicieron asimismo entrevistas a profundidad a autoridades, presentes y pasadas (agrarias, civiles y tradicionales), así como a algunos habitantes de la comunidad. ${ }^{1}$ También

${ }^{1}$ Se realizaron un total de 16 entrevistas abiertas sobre el tema del agua y el territorio en Cuentepec: disponibilidad, organización/manejo, conflictos y gobierno. En este trabajo incluimos citas de algunas de estas entrevistas cuando su contenido ayuda a clarificar el tema que se discute. Siguiendo un principio básico de confidencialidad propio del trabajo antropológico, para salvaguardar la identidad de los informantes - por un acuerdo establecido de antemano con ellos-, modificamos los nombres o bien nos limitamos a citarlos como autoridades o ex autoridades, según sea el caso. 
revisamos los expedientes de la comunidad agraria y del ejido de Cuentepec (1920-2000) en el archivo del Registro Agrario Nacional, en la ciudad de Cuernavaca, Morelos, para reconstruir los procesos de dotación, certificación y conflictos en torno a la tenencia de la tierra. Parte de la información obtenida por estas vías da sustento al presente trabajo.

\section{Cuentepec, una comunidad nahua del centro de México}

Cuentepec es una comunidad indígena nahua de poco más de tres mil habitantes, ubicada en la zona de selva baja caducifolia al surponiente del estado de Morelos, México, en el municipio de Temixco. Sus habitantes dicen haber estado en este territorio desde siempre, desde los antepasados; sólo el sitio del poblado cambió, según cuentan, cuando San Sebastián decidió mudarse del otro lado del río Tembembe y los antiguos se trasladaron siguiendo los designios del santo patrón.

Poco sabemos de su historia en la época prehispánica y del periodo colonial nos llegan, a través de documentos de archivo, sólo algunas noticias sobre litigios de tierras entre los habitantes de San Sebastián Cuentepec y hacendados españoles, ocurridos a todo lo largo del siglo XVIII (Díez, 1933: 279, 324).

El siglo XIX no parece haberles beneficiado mucho en su relación con los hacendados, pues a principios del xx, una vez concluido el proceso revolucionario y al inicio de la nueva reforma agraria que surgió de aquél, los habitantes de Cuentepec solicitaron la restitución de tierras que les habían sido despojadas por alguna hacienda, posiblemente la de Temixco. No obstante, dado que no pudieron comprobar dicho despojo, las autoridades agrarias federales desecharon la solicitud de restitución pero les otorgaron, a cambio, una de dotación. Así el 20 de septiembre de 1923, José Parres, gobernador provisional del estado de Morelos, resuelve dotar a este poblado de una superficie de 3,552 ha de ejido provisional. ${ }^{2}$ La resolución presidencial de dotación definitiva será firmada por el presidente Calles el 1 de septiembre de 1927 y ejecutada el 30 de octubre del mismo año, amparando una superficie de 4,957 hectáreas. $^{3}$

${ }^{2}$ R.A.N. Cuentepec, Expediente 19A, Ramo Tierras Ejidales, Legajo: Tramitación, Fojas: 000026-000028, Visto para resolver el expediente relativo a la restitución o en su caso dotación de ejidos presentada por los vecinos de Cuentepec, municipio de Xochitepec, ex Distrito de Cuernavaca, 20 de septiembre de 1923.

${ }^{3}$ R.A.N. Cuentepec, Expediente 19A, Ramo Tierras Ejidales, Legajo: Ejecución, Foja: 000128, Resolución Presidencial de Dotación, 1 de septiembre de 1927. 
La dotación ejidal de finales de los años veinte no amparaba, sin embargo, la totalidad del territorio reconocido por los habitantes de Cuentepec quienes reclamaban el reconocimiento oficial de 2,279 ha más, de carácter comunal, que según constaba en escrituras de 1890 en su poder, les pertenecían: "No es de más manifestar a usted que dichos terrenos siempre los ha reconocido este pueblo como comunales del mismo pues obran en nuestro poder escrituras de 1890 que acreditan la sana, pacífica y constante posesión de los mismos, pero queremos que dicha posesión esté ajustada a las leyes agrarias en vigor". ${ }^{4}$

El 21 de mayo de 1954 por fin se resuelve la titulación de los bienes comunales de Cuentepec y se reconoce, a favor de este pueblo, una extensión de 2,279 ha bajo un régimen de tenencia comunal. La Resolución Presidencial se publica en el Diario Oficial de la Federación el 26 de octubre del mismo año y el acta de posesión definitiva les es entregada a los comuneros. ${ }^{5}$

Hacia finales del siglo xx y principios del XxI, tras la última certificación de derechos agrarios, el territorio de Cuentepec quedó establecido de la siguiente manera: 4,678 ha de superficie ejidal y 2,390 ha comunales, dando una extensión total de 7,068 hectáreas. ${ }^{6}$

Pese a que el pueblo objeto de nuestro estudio posee un territorio considerable, en lo que se refiere a la calidad del suelo y a los recursos disponibles la situación es distinta. La tierra para cultivar es escasa y pobre. De las 7,000 ha sólo 1,552 están parceladas por ser aptas para la agricultura y 2,214 ha son pastizal y cerril de uso común. El poblado abarca 67 ha y las 3,192 ha restantes corresponden a lo que está clasificado en los expedientes agrarios como ríos, arroyos y cuerpos de agua, lo que corresponde a las barrancas y el cauce del río Tembembe.

Con respecto a la calidad del suelo, desde la dotación temprana a principios de los años veinte, los ingenieros encargados de los estudios daban cuenta de su situación en lo concerniente al ejido. Así, en abril de 1927, el ingeniero Miguel M. Lizama, de la Comisión Nacional Agraria, le informaba a su superior que:

${ }^{4}$ R.A.N. Cuentepec, Exp. 19B, Ramo Tierras Ejidales, Legajo: Ampliación, Foja: 000341, 11 de abril de 1937.

${ }^{5}$ R.A.N. Cuentepec, Exp. 276.1/3 Tomo "A", Ramo: Comunales, Fojas: 089-090 y 098 .

${ }^{6}$ Procuraduría Agraria, Ejido Cuentepec, Actas de Asamblea, agosto 7 de 1999, septiembre 9 de 1999 y septiembre 23 de 1999; Comunidad Agraria Cuentepec, Actas de Asamblea, julio 25 de 1999, septiembre 17 del 2001 y octubre 26 del 2001. 
...las tierras del ejido son excesivamente pobres por lo pedregosas y delgadas. Las de riego no merecen tomarse en consideración pues las aguas del río Atengo que son las únicas de que pueden disponer de manera permanente los vecinos no son aprovechables por estar el lecho muy encajonado. Apenas si uno que otro pedazo puede ser y es cultivado con siembras de hortaliza [...] Las únicas tierras susceptibles de cultivo de temporal, en proporción de un 10\% están situadas en las mesetas de las lomas que separan las barrancas de Atlaco, Coyotomac, Tenestioca, Tlasimaloya y de La Prensa.

En tal sentido puede clasificarse la totalidad de las tierras del ejido como cerril y de pasto. ${ }^{7}$

En 1978, un comisionado de la Promotoría Agraria No. 5, adscrita a la Promotoría Agraria No. 1, informa a su jefe que tanto en los terrenos comunales como en los ejidales, la "calidad de la tierra es pésima, lo que los obliga a salir a trabajar de peones a otros ejidos."

Todavía hoy, comuneros y ejidatarios de Cuentepec (194 los primeros y 421 los otros) $)^{9}$ tienen a la agricultura de temporal para autoconsumo como su principal actividad económica. En parcelas que van de los mil metros (una tarea) a 2.5 ha, siembran maíz, frijol, calabaza, chile y algo de cacahuate; quienes tienen ganado, también cultivan sorgo para alimentar a sus animales. Pero la siembra no es suficiente para dar de comer a las familias a lo largo del año, por ello los cuentepequenses deben complementar su economía con trabajo asalariado fuera de la localidad en temporada de secas (de principios de enero a finales de abril), empleándose de manera fundamental en la industria de la construcción ${ }^{10}$ en la ciudad de Cuernavaca o en la cabecera de Temixco.

Y en lo que respecta al ganado, esa es la gran incógnita. En un territorio de vocación fundamentalmente ganadera no es ésta la actividad más extendida entre los campesinos del lugar. No sabemos con exactitud el número de ejidatarios y comuneros que poseen ganado ni la cantidad de cabezas. En 2004, al momento de levantar un censo de hogares en la localidad, los informantes

${ }^{7}$ R.A.N. Cuentepec, Expediente 19A, Ramo Tierras Ejidales, Legajo: Tramitación, Foja: 000041, 9 de abril de 1927.

${ }^{8}$ R.A.N. Cuentepec, Expediente 19A, Ramo Tierras Ejidales, Legajo: Ejecución, Foja: 000322-000323.

${ }^{9}$ Cabe anotar que algunos ejidatarios también son comuneros, pues poseen ambos tipos de derechos de tenencia.

${ }^{10}$ En un censo de hogares levantado en la localidad en el año 2004 se informa que en $80 \%$ de los hogares, por lo menos uno de sus miembros tiene trabajo asalariado durante la temporada de secas y de éstos, $50 \%$ se emplea como peón de construcción y $26 \%$ como jornalero agrícola. Un peón de construcción gana entre $\$ 120$ y \$150 al día, lo que equivale a entre 11 y 14 dólares. 
trataban de eludir esa pregunta pues tiene implicaciones en la percepción que sobre ellos tienen los demás miembros de la comunidad. Criar ganado significa tener dinero y eso, a su vez, implica que deben asumir localmente cargos cívicos, ceremoniales o agrarios, lo que siempre resulta oneroso para las economías domésticas. El cálculo que podemos obtener a partir de nuestro censo es de aproximadamente $30 \%$ de ejidatarios y comuneros con ganado. Con respecto a los hatos, ningún informante nos dijo tener más de cinco cabezas; sin embargo, hay quienes mencionan que algunos ejidatarios y/o comuneros tienen entre $20 \mathrm{y}$ 40 vacas y que alguno de ellos llega a tener hasta 600 animales. Sea como fuere, lo que es una realidad es que las poco más de 2,000 ha de pastos de Cuentepec no las aprovechan sólo quienes tienen derechos de tenencia sobre ellas. Sobre esto hablaremos más adelante.

Si bien el pueblo de Cuentepec se encuentra ubicado en los márgenes del río Tembembe ${ }^{11}$ (también llamado Atengo), y éste atraviesa por su territorio separando los bienes comunales de los ejidales, ello no significa que su población se haya beneficiado de la disponibilidad del recurso agua. En lo que al riego se refiere, de los cerca de 500 campesinos con derechos de tenencia comunal o ejidal, sólo 60 tienen concesión de agua para riego en pequeñas parcelas de una tarea (mil metros) o menos, pues no alcanza para más. Por otro lado, en lo que respecta a la disponibilidad del recurso para uso doméstico, la situación no es mejor. Prácticamente a todo lo largo de la historia de este asentamiento, procurarse el agua significó dedicar tiempo y esfuerzo para descender una cañada de entre 150 y $200 \mathrm{~m}$ de profundidad a las orillas del río, en una pendiente muy pronunciada, y transportar el líquido en la espalda en cántaros atados por la cabeza o, en el mejor de los casos, cargados en bestias, como se relata en un informe de la Comisión Nacional Agraria en el año 1927 y nos fue reiterado, de igual forma, en distintos testimonios durante nuestro trabajo de campo.

No solamente falta el agua para riego, sino que hasta para los usos domésticos pues los vecinos para adquirirla tienen que bajar a una profundidad de no menos de 150 metros en zig-zag hasta el río, de donde la

${ }^{11}$ El río Tembembe es afluente del Amacuzac que, a su vez, es tributario del Balsas. La cuenca de este río se localiza al noroeste del estado de Morelos y el sureste del Estado de México (Gómez Garzón, 2000: 1). 
suben en cántaros y a lomo de bestias los que de ellas disponen, invirtiendo en el viaje de hora a hora y media (R.A.N., 1927, loc. cit.).

Más antes, del río íbamos a acarrear como a las seis de la mañana, con cántaros y con bule aquí colgado, con los cántaros atrás. Íbamos al río temprano, como dos veces al día teníamos que ir a acarrear para tomar y para usar, íbamos las mujeres y los hombres, todos (Cuentepec, marzo de 2005, entrevista con doña Yolanda).

En el año de 1953, ante la dificultad para abastecerse de agua, el pueblo de Cuentepec firma un convenio de amistad con sus vecinos de Ahuatenco, municipio de Ocuilan, Estado de México (con quienes colindan hacia el norte), a través del cual se establece que éstos proporcionarán agua corrediza de un sitio llamado Mexicapan, a cambio de poder meter su ganado a pastar en los terrenos ejidales de Cuentepec. ${ }^{12}$

Con trabajo y recursos comunitarios, y sin ningún tipo de apoyo oficial, los vecinos de Cuentepec construyeron un canal a través del cual corría el agua que llegaba a esta comunidad.

Me acuerdo tantito cuando entró el agua [...] Dicen que se pusieron de acuerdo y cooperaron y se pagó a los que trabajaron. Primero se hizo un canalito, no me acuerdo si tardó un año o en cuánto tiempo se hizo para terminar bien. Primero era un apantle, un canal, pues [...] El primero, cuando era canal, ese fue pagado por la comunidad (Cuentepec, junio de 2003, entrevista con ejidatario).

Durante treinta años Cuentepec obtuvo agua de Mexicapan, aunque ésta no se podía usar para tomar pues venía muy sucia: "Bien sucia venía, por la tierra de allá, y el agua venía como chocolate", nos refieren varios testimonios; así que complementaban el abasto con el agua del río, pues esa "sí se podía tomar".

En los años ochenta, según lo refiere un ex ayudante municipal, Ahuatenco le propone a Cuentepec un cambio:

¿Por qué no nos dejan esta agua (la de Mexicapan) a nosotros?, para cultivar, y les vamos a dar otro manantial, ese es muy limpio, es agua potable para tomar. Si nos deja ésta les vamos a dar esa (Cuentepec, marzo de 2005, entrevista con un ex ayudante municipal).

Así, a principios de los años ochenta se actualiza el convenio con Ahuatenco quien le otorga a Cuentepec la cantidad de 6 li-

12 Cabe mencionar que Ahuatenco es uno de los múltiples asentamientos de la comunidad agraria de Ocuilan, Estado de México, cuya extensión territorial es de poco más de 41,000 hectáreas. 
tros por segundo del manantial de la Amapola, ubicado también en el territorio de Ocuilan, Estado de México, pero en esta ocasión el agua ya no vendrá a través de un canal abierto sino de tubería. El gobierno del estado de Morelos cubrió los gastos que implicó la conducción del agua, pero no hizo ningún pronunciamiento sobre las condiciones del convenio.

Las negociaciones entre Cuentepec y Ahuatenco por el agua no han sido sencillas, y si bien en los años ochenta el gobierno de Morelos contribuyó económicamente para entubar el agua, lo cierto es que ha predominado la ausencia del Estado en un asunto que indudablemente le compete en tanto que el agua es de la nación, según reza el artículo 27 constitucional, y su abasto a la población es, por tanto, un asunto de interés público. Volveremos sobre este punto más adelante; baste por ahora mencionar que la comunidad indígena de Cuentepec ha estado sola en todo este proceso, y sola también ha tenido que enfrentar y resolver diversos conflictos con sus vecinos, pues la comunidad agraria de Ocuilan, a la que pertenece el pueblo de Ahuatenco, se siente la dueña de los terrenos de agostadero, y sus autoridades aprovechan la menor provocación para cortarles el agua a los cuentepequenses, no obstante el convenio de amistad que firmaron con ellos.

En los últimos veinticinco años, Cuentepec ha negociado con Ocuilan en dos ocasiones la cantidad de suministro de agua: primero 6 litros por segundo, y en 2003 solicitaron que la cantidad se incrementara a 15 litros por segundo, lo que todavía no han logrado. Durante este tiempo también han tenido que enfrentar por lo menos cuatro conflictos fuertes con sus vecinos en sus negociaciones de agua por pastizal y, en todos los casos, a excepción del último que aún no se ha resuelto, la balanza no se ha inclinado a su favor. El primero de ellos ocurrió cuando canalizaron el agua a través de tubería: si bien el gobierno del estado pagó la obra, no procuró ayuda en la tramitación de permisos con el ayuntamiento de Ocuilan, y el comité de agua de Cuentepec fue detenido por los habitantes y la policía montada de aquel municipio, quienes los acusaban de estar invadiendo su territorio.

Cuando empezamos abrir la brecha para hacer los trabajos de la línea de conducción en ese mismo año, en los años 81-82, no recuerdo qué fecha ni qué mes, el presidente de bienes comunales traía la policía montada de Ocuilan, nos mandó traer en calidad de detenidos, nada más a nosotros, los del comité [de agua]. Llegamos aquí a casa del señor Ramón Camacho, que era el delegado municipal [de Ocuilan en Ahuatenco] en aquel tiempo; pues ahí estaban en una reunión con otros 
señores de Ahuatenco y ahí nos preguntaron: “¿Pues qué?, ¿qué pasó?, ¿por qué no sacaron permiso para hacer la brecha?

$\mathrm{Y}$ es cierto, es lo que nos hizo falta, no solicitamos [permiso] para hacer la brecha, para hacer los trabajos.

Entonces, como nos conocemos Ahuatenco y Cuentepec, ellos mismos nos defendieron, unos pues, no todos; algunos estaban en contra de nosotros, hasta nos querían pegar. Ya cuando se les empezó a platicar que dentro de unos días se metía la solicitud pidiendo que sí, para que nos dejaran trabajar, para hacer la brecha. Entonces el presidente vecinal dijo que nos esperaba en sus oficinas, que lleváramos el escrito, y ya nos dejaron, pues (Cuentepec, abril de 2005, testimonio del ex ayudante municipal).

Algunos años más tarde, en la misma década de los ochenta, durante la administración de Lauro Ortega, el gobierno del estado de Morelos promovió un programa de cría de ganado para Cuentepec y para ello cercaron los pastizales de esta comunidad hasta sus límites con el Estado de México. Ahuatenco reaccionó de inmediato cortando el suministro de agua del Amapola.

Cuando fue gobernador don Lauro Ortega, quería meter ganado aquí, todo el ejido, de aquí para allá arriba que colinda con el Estado de México; quería meter ganado de cría [...] Tomaron acuerdo el comisariado con los ejidatarios que sí, que iba a trabajar mucha gente, y cercaron todo hasta el límite con Estado de México, con Ahuatenco; cercaron todo el terreno con cinco hiladas de alambre; trajeron como tres tráilers de alambre. Iban a hacer un potrero para ganado, y luego en otra parte iban a hacer presas para que tomaran agua, y los de Ahuatenco se enojaron [...] y así ya no se hizo nada porque cortaron el agua y ya no trajeron el ganado, ya no se hizo el programa pues don Lauro dijo: "No queremos problemas" (Cuentepec, marzo de 2005, entrevista con ex comisariado ejidal).

La respuesta del gobierno del estado al problema de abasto de agua de Cuentepec fue doble: por un lado canceló de inmediato el proyecto ganadero, con lo que negó a los campesinos la posibilidad de diversificar su economía; y por otro, decidió perforar un pozo profundo que abasteciera a la población in situ; sin embargo, el pozo funcionó por poco tiempo pues pronto se descompuso la bomba y la comunidad no tuvo forma de mandarla a arreglar; en primer lugar, porque no tenían dinero para hacerlo, en segundo porque no contaban con lo papeles que los acreditaban como beneficiarios.

En aquel tiempo no pagábamos la luz, así nomás, y luego, cuando se descompuso, íbamos la comisión a Temixco, a Cuernavaca, pero nos pedían papeles y pues no teníamos papeles, y de ahí la Comisión [Fede- 
ral de Electricidad] nos dijo que no lo iba a arreglar porque no teníamos papeles y ahí se perdió el pozo (Cuentepec, marzo de 2005, entrevista con ex comisariado ejidal).

Sin pozo y sin programa ganadero, Cuentepec volvió a negociar agua por territorio con sus vecinos de Ocuilan.

Llama la atención que el gobierno del estado de Morelos, en lugar de asumir su responsabilidad como representante de los intereses de la población, en especial de ésta tan desprotegida y vulnerable, optara por perforar un pozo y también por cancelar el proyecto ganadero, para evitar conflictos con Ocuilan, en lugar de hacer las negociaciones necesarias para que el gobierno federal, que era la instancia que desde principios del siglo Xx había tenido bajo su control todo lo referente al uso, aprovechamiento y gestión de este recurso (Aboites, 1998), le pusiera un alto a los abusos de ese municipio del Estado de México que, sin tenerlos, se sentía con todos los derechos.

¿Cómo interpretaban las autoridades del estado el precepto constitucional que indica que el agua es de la nación? ¿Por qué permitieron que una comunidad tan pobre como Cuentepec, que para los años ochenta no tenía siquiera una carretera que la vinculara con el resto de la entidad, estableciera un convenio con sus vecinos en condiciones tan desventajosas, cuando la dotación de agua a la población es un derecho básico que se debe cumplir sin condiciones? Una de las posibles respuestas pudiera ser que no hayan querido entrar en ningún tipo de conflicto con el poderoso Estado de México; otra, vinculada a la anterior, es que no consideraban importante ni a la población de Cuentepec ni a su territorio; a fin de cuentas se trataba de una pequeña comunidad indígena cuyos habitantes ni siquiera hablaban bien español; era claro que ni ellos, ni sus tierras, ni sus recursos eran significativos económica ni políticamente para el gobierno del estado.

La negociación de agua por territorio le ha generado a Cuentepec incluso conflictos internos: según se desprende de documentos de archivo, en diversas ocasiones durante los años ochenta y noventa campesinos sin tierra de esta comunidad abrieron y cercaron terrenos de cultivo en tierras de pastoreo objeto del famoso convenio, provocando con ello el reclamo inmediato de Ocuilan. Internamente, las autoridades agrarias de Cuentepec 
nunca reconocieron los derechos de los campesinos demandantes y los conflictos se dirimieron a favor de Ahuatenco. ${ }^{13}$

Hablando con uno de los líderes de la comunidad, quien no sólo ha tenido los principales cargos de autoridad en el pueblo (civiles y agrarios), sino que también ha participado en las negociaciones con Ocuilan desde que era joven en los años ochenta, éste nos indicó con mucha claridad que, desde su punto de vista, el asunto del agua ha sido complicado debido por lo menos a tres razones: primero, porque Ocuilan se siente dueño tanto del agua como de los terrenos de agostadero del norte del ejido de Cuentepec; segundo, porque las autoridades de la entidad no se han involucrado en el asunto ni los han apoyado en sus negociaciones, ni siquiera la presidencia municipal de Temixco; y por último, porque hasta hace muy poco tiempo, apenas hace unos cuatro o cinco años, fue cuando ellos, los de Cuentepec, se enteraron que su convenio de buena vecindad no tiene ninguna validez jurídica, pues el agua es de la nación y la concesión de derechos se debe tramitar a nivel federal, ante la Comisión Nacional del Agua (CNA), y no negociarse con otras comunidades sólo porque en su territorio se encuentren los manantiales.

La visión de este líder, en especial en lo que se refiere al último punto, no está sin embargo muy extendida, ya no se diga entre la población de Cuentepec, ni siquiera entre las autoridades agrarias y civiles actualmente en funciones, y que son las que deben seguir negociando para ampliar la disponibilidad de 6 a 15 litros por segundo. Éstas saben ya que los trámites de la concesión del agua deben realizarse en las oficinas de la Comisión Nacional del Agua en Cuernavaca, capital del estado, y que la negociación, en todo caso, debe darse con los concesionarios legalmente reconocidos, que no son los de Ocuilan, sino sus otros vecinos de Miacatlán-Vaso el Rodeo; no obstante, opinan que al mismo tiempo deben convencer a los del Estado de México para que cedan, y para ello están dispuestos a cumplir con sus demandas. Parece que continuar con el trueque de agua por territorio no está del todo en discusión. ¿Y por qué habría de estarlo si desde su percepción los terrenos de agostadero son vastos $(2,214$ ha), especialmente si se comparan con las minúsculas parcelas de cultivo (de una a tres ha) que detenta cada familia campesina de esa localidad? Las tierras de pastoreo, su territorio de uso

${ }^{13}$ R.A.N. Cuentepec, Ramo: Derechos Agrarios, Expediente 278.2/19, Tomo A, Folios 000239, 000258, 000647, 000655, 000656. 
común, es el activo de que dispone la comunidad para enfrentar sus carencias.

A lo largo de nuestro trabajo de campo, cuando en las entrevistas preguntamos si los pastos de ejido y comunidad eran suficientes para el ganado, tanto local como foráneo, todos nuestros entrevistados respondieron igual: "Tenemos harto pasto, nunca nos falta”, "Es mucho terreno, hay mucho”. Y puede ser que sí sea cierto todavía, pero no por mucho tiempo, pues nadie sabe cuánto ganado está pastando en los terrenos de Cuentepec y las autoridades locales hacen cuentas alegres sobre el índice de agostadero, el cual calculan entre cinco y siete cabezas por ha, lo que es impensable siquiera en el trópico húmedo donde es de $1.5 \mathrm{c} /$ ha. Algunos especialistas hablan de una relación inversa, es decir, 5 ha por cabeza. ${ }^{14}$

De los pastos de Cuentepec come el ganado de comuneros y ejidatarios de esta localidad, el cual calculamos, conservadoramente, en alrededor de 800 cabezas; también lo hace el ganado de Ahuatenco y de otras localidades de Ocuilan, amparados por el Convenio de 1953; entra ganado de varios ejidos del municipio de Miacatlán y también de Temixco. Con los ejidos de estos dos municipios no hay convenio de por medio, pero algunos de ellos pagan una pequeña cuota anual de entre 200 o 300 pesos por ganadero, misma que entra a la caja de los Comisariados de Bienes Ejidales o Comunales, según sea el caso, y permite con ello que estas instancias, paradójicamente encargadas de regular el uso de los bienes comunes, cubran algunos de sus gastos, entre otros los de las comisiones cuando tienen que ir al Estado de México a negociar el agua. Así lo expresó quien fuera en otros tiempos presidente del comisariado ejidal.

El ganado que viene de fuera lo meten como de mayo a enero, como diez meses, de marzo a abril se lo llevan a comer en sus casas porque ya se está acabando el pasto, aunque no acaba, lo termina la lumbre [...] Tenemos problema con el ganado que se mete a las milpas, luego a veces los ejidatarios dicen que ya no les den, que ya no los dejen entrar, porque hacen daños, y también porque se acaba el pasto, así dicen, que ya no alcanza; pero no lo dicen todos, sólo los que tienen ganado y a los que les hacen daños. Pero, si les decimos que ya no metan el ganado, ¿de dónde va a salir el dinerito para los gastos? De ahí sale para las comisiones [...] No pagan mucho, son como 300 pesos por ganadero y pagan de los dos lados, con don S [presidente del comisariado de bienes comunales] y con don $G$ [presidente del comisariado de bienes

${ }^{14}$ Doctor Raúl García Barrios, comunicación personal. 
ejidales] (entrevista con el ex presidente del Comisariado de Bienes Ejidales, marzo de 2005).

Independientemente de si los forrajes alcanzan o no para alimentar a todo el ganado que pasta en el territorio de Cuentepec, lo que es una realidad es que aquí se vive una situación de acceso abierto, sobre la que las instituciones agrarias locales ya no tienen ningún control. El problema mayor, desde nuestro punto de vista, no estriba tanto en la disponibilidad de alimento, lo que de suyo es importante, sino en las consecuencias de erosión y compactación de suelos provocadas por el sobrepastoreo, hecho que hoy ya es una evidencia según se desprende de un estudio del Instituto Mexicano de Tecnología del Agua, que reporta una erosión de entre 30 y 40 ton/ha/año, con tendencia al aumento (Gómez Garzón, 2000: 16). Esto, a nuestro parecer, es la principal amenaza que se cierne sobre el futuro, no muy lejano, de las tierras de pastoreo de esta comunidad.

\section{Identidad y sentido de pertenencia territorial: una ecuación necesaria pero insuficiente para la sustentabilidad}

La vida de Cuentepec en todas sus dimensiones, es decir, la cotidiana, la ritual, la económica, la política, la social y la cultural, está marcada por el ciclo agrícola. Sus habitantes son, principalmente, campesinos temporaleros de subsistencia que siembran, y han sembrado desde siempre, el maíz y el frijol que los alimenta.

El 3 de mayo celebran con fuegos pirotécnicos y campanas de la iglesia el día de la Santa Cruz, fiesta de los albañiles, pero la fecha también les recuerda que las lluvias no tardan en llegar y que hay que comenzar a preparar el terreno de cultivo. A partir de este momento, los hombres adultos pasarán la mayor parte del día en sus parcelas de cultivo preparando el terreno; sus mujeres les llevarán el almuerzo a media mañana y les tendrán preparada la tortilla para cuando regresen de noche; y sus hijos, los grandecitos, se les unirán en las labores del campo a partir de junio cuando termine el ciclo escolar.

Limpiar, barbechar y sembrar son las tareas que ocupan, de sol a sol y de lunes a domingo, el tiempo de los campesinos de Cuentepec desde mediados de mayo hasta mediados de agosto, cuando la milpa ya empieza a espigar. En este momento, algunas familias de este pueblo, las que heredaron de sus antepasados la piedra de los aires o de los vientos, ponen una ofrenda para esta deidad, a la que le agradecen haber traído las lluvias necesarias 
para la siembra, pero en sus oraciones le ruegan que se vaya, que regrese a las montañas donde tiene su casa, para no hacer daño ni a la gente ni a los cultivos.

Dado que hay varios hogares con piedra en el poblado ${ }^{15}$ y la colocación de la ofrenda es labor de un especialista, de los que sólo hay dos en la localidad, las ofrendas a los vientos comienzan a colocarse del 15 de agosto a mediados de septiembre, aproximadamente, para terminar antes del 29 de ese mes en que tiene lugar la fiesta de San Miguel Arcángel, el otro santo patrono de Cuentepec (González, 2005).

Agosto marca el inicio del calendario ritual vinculado al ciclo agrícola, pero es también el mes en que los adultos de esta localidad eligen a su autoridad cívico-religiosa, el ayudante municipal, quien se desempeñará en ese cargo a lo largo de un año. Él será el encargado de organizar y solventar las dos fiestas principales del pueblo, la de San Miguel, a fines de septiembre y la de San Sebastián, a mediados de enero. Con el primero se festeja que la milpa ya está eloteando, que ya salió el fruto que habrá de convertirse en maíz; con el segundo se agradece la cosecha y se marca el fin del ciclo agrícola.

El ayudante municipal, junto con los Principales del pueblo, preside ambas celebraciones, pero también tiene entre sus tareas, además de las ceremoniales, ser la principal autoridad política de la localidad. Él es el encargado del ayuntamiento en el pueblo, a la vez que representa a su población ante aquél; es por tanto, el enlace con las autoridades municipales, estatales y federales. Las decisiones más importantes pasan por él, por lo que tiene que mantener una estrecha coordinación con los diversos comités (de agua, de obras, de salud o los que hubiere) y con las autoridades agrarias del ejido y la comunidad; y debe también, en aras de su buen desempeño de gobierno, mantener un diálogo abierto con la asamblea general la que, en primera y última instancia, sanciona todas sus acciones. En el caso de las negociaciones y/o conflictos con los pueblos vecinos, el ayudante municipal es quien juega el papel principal.

A finales de enero, cuando se levantó la cosecha y tras la fiesta de San Sebastián, la mayoría de los varones adultos de la comunidad sale a buscar trabajo asalariado en la capital del estado (en las obras de construcción) o en los ejidos y/o propiedades cercanas que tienen tierras de riego y demandan mano de obra

${ }^{15}$ Según nuestro censo de 2004, de un total de 678 hogares, 76 cuenta con la piedra de los aires y de éstos, 67 continúa poniéndole ofrenda. 
para la siembra de arroz, de hortalizas o para la cosecha de rosas. La mayor parte de los que se emplean como jornaleros agrícola son los adultos mayores de 40 años, pues los jóvenes prefieren el trabajo en las ciudades (Censo de Hogares de Cuentepec, 2004). ${ }^{16}$ El trabajo asalariado que se desarrolla de enero a mayo servirá para complementar la economía de las unidades domésticas, y para adquirir un poco de efectivo que les permita arreglar o construir sus viviendas, o bien para sufragar los gastos de las bodas en las familias, las que normalmente se llevan a cabo en el mes de mayo, antes de que comience el trabajo duro en el campo y vuelva a comenzar el ciclo.

Vista así, Cuentepec se nos presenta como una comunidad campesina indígena que se organiza, vive y celebra en función de la siembra. Mantiene activas sus instituciones de gobierno tradicionales y su sistema de cargos cívico-religiosos. No obstante su cercanía con la ciudad de México, a menos de $100 \mathrm{~km}$ y con sólo $20 \mathrm{~km}$ de distancia de Cuernavaca, la capital del estado de Morelos, los habitantes de Cuentepec se distinguen del resto de la población del estado por su orgullo nahua. Han mantenido vivas a lo largo del tiempo costumbres, tradiciones ${ }^{17}$ y lengua, y ésta última de manera consciente y decidida pues toda su población es hablante: desde los niños pequeños hasta los adultos mayores. En la escuela primaria la educación es $100 \%$ bilingüe y los lunes comienzan honores a la bandera entonando el himno nacional en su lengua materna. Las mujeres de la comunidad, por su parte, visten cotidianamente su traje tradicional compuesto de faldas plizadas y delantales que ellas o sus madres confeccionan; algunas elaboran piezas de barro, y todas transmiten a sus hijas sus conocimientos sobre plantas medicinales, elaboración de platillos, crianza y cuidado de animales de traspatio y, en general, todo lo que refiere a las costumbres en la vida doméstica.

Podríamos decir que Cuentepec es una comunidad indígena que a través de sus prácticas y su quehacer cotidiano reafirma

${ }^{16}$ La migración internacional es un fenómeno reciente y todavía incipiente. Según la información proporcionada por el censo, encontramos que de 1998 hasta 2004, del total de la población $(3,126)$ sólo 109 individuos habían viajado a los Estados Unidos a trabajar, y de este total, 54\% (59 personas) fue a trabajar un año o dos y ya estaban de regreso en el pueblo; 41\% (45 individuos) residían en ese momento en los Estados Unidos y 5\% (cinco personas) presentaban un patrón de migración temporal pues se contrataban anualmente a través del programa de trabajadores migratorios.

${ }^{17}$ No suponemos que se hayan mantenido de manera intacta costumbres y tradiciones en esta comunidad a lo largo del tiempo; su particular articulación con los ámbitos nacional e internacional sin duda han impactado e incidido en su reconfiguración, creación y recreación. 
sus costumbres y sus creencias profundas, su identidad étnica y su sentido de pertenencia a un territorio ocupado por ellos a lo largo de los siglos y, sin embargo, esto no es suficiente para defenderlo ni para garantizar la sustentabilidad de sus recursos, ¿por qué?

En otros trabajos de investigación encontramos interesantes experiencias de acción colectiva en el manejo y conservación de los recursos naturales, vinculadas a construcciones identitarias y fuertes sentidos de territorialidad (Toledo, 2000; Paz, 2005; Canabal et al., 2006); no es el caso en Cuentepec. La acción colectiva en torno a la conservación y el manejo de los recursos surge vinculada a una identidad compartida, la que a su vez da forma a instituciones normativas locales. En el caso que aquí presentamos, no hay acción colectiva con estos propósitos porque las instituciones que existen no están destinadas a normarla y orientarla, pues se dirigen a otros aspectos de la vida social. ¿Significa esto acaso que en Cuentepec no hay territorialidad como construcción colectiva? Sí la hay, pero está construida con otros referentes.

Desde la geografía, algunos autores que trabajan con los conceptos de territorio y territorialidad indican que éstos remiten a una representación social del espacio que une al interior y separa del exterior; es decir, es tanto incluyente como excluyente (Tizon, 1996: 23-29). Otros más indican que la construcción colectiva de la noción de territorio refiere al espacio apropiado por un grupo social para garantizar su sobrevivencia y reproducción: "El territorio [...] es aquella porción del espacio apropiada por las sociedades humanas para desplegar en ella sus actividades productivas, sociales, políticas, culturales y afectivas, y a la vez inscribir en ella sus estrategias de desarrollo y, todavía más, para expresar en el curso del tiempo su identidad profunda mediante la señalización de los lugares” (Lecoquierre y Steck, 1999, citado por Giménez, 2004: 47).

Cuentepec construye su territorialidad a través de sus prácticas productivas agrícolas y la organización cívico religiosa estructurada en torno a ellas; es así como construye territorio, lo dota de sentido y lo delimita hacia fuera. Asimismo, el carácter endogámico que se aprecia en el hecho de que $98 \%$ de sus habitantes son originarios del lugar, el fuerte arraigo de su población ${ }^{18}$ y la persistencia de un patrón de residencia patrivirilocal,

${ }^{18}$ Según nuestro censo, de la población total nacida en Cuentepec, 97\% vive ahí. 
que mantiene a los hijos varones casados viviendo en la casa de sus padres para evitar que las parcelas de tierra que les pertenecen pasen a manos de terceros, nos remite sin duda también a ese carácter incluyente-excluyente del territorio con el que sus poseedores construyen territorialidad: Cuentepec es para los cuentepequenses. "Si dejamos que vengan otros de fuera, se van a sentir dueños", nos dijeron cuando preguntábamos por qué no vivía gente de otro lugar en el pueblo. Sin embargo, llama la atención que esta máxima no aplique en el caso de las tierras de pastoreo, donde, efectivamente, los de Ocuilan se sienten con todos los derechos y así los reclaman cada vez que pueden. Nuestra hipótesis apunta en el sentido de que más que un descuido o falta de sentido territorial, este hecho responde más bien a una estrategia de doble propósito: tanto para mantener el control político interno, a través de sus propias instituciones, como para enfrentar una situación de escasez históricamente construida. Veamos esto.

Como se mencionó líneas atrás, el territorio de Cuentepec es fundamentalmente de vocación ganadera; no obstante, aunque algunos de los comuneros y/o ejidatarios puedan dedicarse a esta actividad, la comunidad en sí no se siente ganadera, no se define como tal; es más, mientras menos se note que lo es, mejor. ¿Por qué tanto secreto y tanto sigilo? En primer lugar habría que aclarar que la gran mayoría de quienes tienen vacas, en efecto tiene hatos de sólo tres o cuatro animales, esa sí es una realidad, y ello explica en parte que no puedan sentirse ganaderos; pero aquellas familias que tienen más prefieren que esto no sea muy notorio pues no es bien visto, genera envidias y obliga, en una economía de prestigio, a compartir y distribuir la riqueza a través del oneroso sistema de cargos o las contribuciones en las fiestas. ${ }^{19}$ Eso desprendemos de nuestro censo y entrevistas y lo encontramos también en otros estudios. Landázuri (1997) documenta cómo un grupo de campesinos de este poblado esgrime como argumento para no aceptar un programa de crédito para ganadería de doble propósito propuesto por el entonces Instituto $\mathrm{Na}-$ cional Indigenista, el hecho de que la comunidad les exigiría a ellos, como ganaderos, una mayor cooperación: "Nos van a decir: tienen que cooperar, ustedes son ganaderos [...] están recibiendo del gobierno, tienen que poner un animal para la fiesta

${ }^{19} \mathrm{Al}$ respecto, Landázuri (1997) indica que a finales de los años noventa existían cuotas diferenciadas de cooperación para las fiestas, siendo la más alta la de los ganaderos, maestros y/o los propietarios de camioneta. Hoy tal vez están dentro de esa lista las familias que reciben remesas de sus familiares en los Estados Unidos. 
[pero] nosotros estamos pagando y ya no nos conviene" (Landázuri, 1997: 12).

Así, el convenio con Ocuilan y todos los permisos para que pastoree el ganado de otros ejidos en su territorio se puede interpretar como una forma de control social interno que se ha instituido en esta comunidad, para evitar que se expandan algunas de las familias que tienen ganado y sólo ellas se beneficien de un bien colectivo como son los terrenos de uso común. En la transacción de agua por territorio, la comunidad le da a éste un carácter de bien público que permite que toda la población se beneficie. El punto de tensión está, empero, en que la institución que genera el bien común, paradójicamente, no garantiza ni procura su sustentabilidad. Desde nuestra perspectiva ello no obedece a una falla de la institución o a su incapacidad innata, como sería el argumento de la Escuela de Derechos de Propiedad (Property Rights School), que critica a la propiedad colectiva con el argumento de la tragedia de los comunes planteado por Hardin en 1968 (Baland y Platteau, 1996). Nosotros consideramos más bien que el punto está en que se trata de una institución diseñada con otros propósitos, que surge de, y está vinculada a, la identidad y la territorialidad de los campesinos-indígenas-milperos-temporaleros-de autoconsumo, para enfrentar y poder administrar las condiciones de escasez del colectivo a través de la imposición de límites internos. Y esto nos lleva a nuestro segundo elemento de reflexión.

Podríamos decir que Cuentepec es una comunidad muy pobre y que es la pobreza la que los obliga a degradar sus recursos. No es así. Cuentepec, como muchas comunidades indígenas de nuestro país, y en realidad de toda América Latina, ${ }^{20}$ padece, más bien, una situación de escasez. Hay escasez en recursos naturales: sus suelos son pobres y no aptos para la agricultura, la tierra de riego es limitada y el agua es escasa y de difícil acceso. Se observa asimismo escasez económica de sus habitantes quienes con dificultad viven al día, no obstante que invierten todo su tiempo y energía en ello combinando el trabajo agrícola de autoconsumo (100\% de los hogares encuestados) con el trabajo asalariado poco calificado y, por tanto, mal pagado, ${ }^{21}$ en las ciuda-

${ }^{20}$ Véase el trabajo de Cimadamore et al. (2006).

${ }^{21}$ Tanto en la industria de la construcción como en el trabajo de jornalero agrícola, en 2004 el salario oscilaba entre \$ 120 y \$ 150 por día, lo que equivalía a tres o un poco más de tres salarios mínimos que, para ese entonces, estaban estipulados en 42.11 pesos. 
des cercanas ( $80 \%$ de los hogares). ${ }^{22}$ Se observa también escasez política: sus instituciones de gobierno son débiles y están desgastadas, sus pocos líderes y la larga historia de control político interno y externo a ratos los inmoviliza y los encierra, los ata al pasado y les niega la posibilidad de crecer internamente o bien generar alianzas regionales que los fortalezcan. Por último, los datos nos hablan asimismo de una escasez de Estado, en tanto institución garante del interés público. Plantear el problema en términos de escasez y no de pobreza, nos lleva a verlo entonces no como una condición dada o como una característica propia que pudiera superarse a través de la modernización o de un programa de gobierno, sino como una construcción sociopolítica de carácter histórico (Cimadamore et al., 2006) que requiere enfocarse desde una perspectiva de poder para dar cuenta de que la ecuación no está compuesta por territorio-cultura-sustentabilidad, sino a través de la articulación entre territorio-poder-comunidad indígena-Estado.

A lo largo de su historia reciente, Cuentepec se ha visto obligado a intercambiar agua por territorio, la condición de escasez los ha orillado a ello. La situación, sin afán de dramatizar, es bastante grave por varias razones. Por un lado, este convenio intercomunitario, de buena vecindad pero sin sustento jurídico, les ha quitado (una vez más) autonomía en sus decisiones al interior de su territorio, pues sus vecinos piensan que también les pertenece a ellos y, por tanto, los deben consultar o hasta pedir permiso en cualquier decisión. ${ }^{23}$ Por otro lado, al no haber ninguna instancia reguladora, se ha generado una situación de acceso abierto en los terrenos de agostaderos, lo que expone sus suelos a un franco deterioro por sobrepastoreo, sin que se haga nada

${ }^{22}$ Así como la agricultura milpera-temporalera es la principal fuente de subsistencia de los pobladores de Cuentepec, el trabajo asalariado fuera de la localidad es la principal fuente de ingreso monetario. Desde el siglo pasado, según se desprende de los documentos de archivo, los habitantes de Cuentepec complementan su economía de autoconsumo con el trabajo asalariado fuera de la localidad. Actualmente, $80 \%$ de los hogares (542) informa que al menos uno de sus miembros se contrata en algún trabajo asalariado fuera de la localidad. Las personas que trabajan fuera de la localidad (721) se contratan fundamentalmente en: la industria de la construcción (56\%), como jornaleros agrícolas $(20 \%)$ y en trabajos domésticos $(13 \%)$. El 10\% restante se reparte entre comercio eventual, magisterio y empleados públicos.

${ }^{23}$ En 2003, la Universidad Nacional Autónoma de México presentó a la asamblea de Comuneros y Ejidatarios de Cuentepec un proyecto para establecer una estación biológica de restauración de barrancas en el territorio de esta comunidad. La asamblea lo aprobó y designó una superficie de 100 ha en la ladera de una barranca para que se estableciera la estación y comenzaran los trabajos de restauración. Al poco tiempo, vecinos de Ahuatenco se presentaron ante el personal de la UNAM que estaba trabajando en el lugar, pidiendo que se les explicara qué estaban haciendo ahí. 
para detener este proceso; por último, la gran paradoja está en que, no obstante todas las desventajas y consecuencias del convenio, la población de Cuentepec no ha resuelto el problema del abasto de agua pues ésta es escasa y no alcanza: 70\% (476) de los hogares recibe agua cada tercer día durante dos horas; $20 \%$ (142) cada semana por el mismo lapso y $7 \%$ no recibe agua desde hace más de un año por la falta de presión con que ésta viene, lo que obliga a estas familias a comprarla, pedirle a los vecinos o bajar al río a buscarla (Censo de Hogares, 2004).

En este trabajo nos preguntamos de inicio si existía una relación directa entre la identidad cultural, el sentido de pertenencia territorial y la sustentabilidad; con lo aquí presentado vemos que no necesariamente. La experiencia reseñada nos muestra que la identidad de campesinos-indígenas-milperos-temporaleros-de autoconsumo, construida y sustentada por los habitantes de Cuentepec tiene, en efecto, un fuerte arraigo territorial, una referencia directa a su espacio geográfico y su entorno físico pero que es la condición de escasez construida desde que esta comunidad perdió control sobre el territorio (primero por culpa del santo patrono, San Sebastián, como cuenta la leyenda antes referida, después por los hacendados del siglo XIX y, finalmente, por el Estado mexicano posrevolucionario que, por un lado, no les reconoce el derecho de restitución de tierras y después los margina como población indígena prácticamente a todo lo largo del siglo xx) la que provoca que las instituciones locales se vuelquen hacia el control interno para garantizar que el territorio, en particular los bienes de uso común, sean recursos que beneficien a la colectividad y no sólo a una porción de ésta.

La gran paradoja es que en aras del bien común se generó una situación de acceso abierto que expone los terrenos de pastoreo al deterioro, y Cuentepec no tiene una institución que pueda normar al respecto y proteger así su patrimonio.

\section{Algunas reflexiones finales}

El caso que aquí presentamos refiere, efectivamente, a una pequeña comunidad indígena del surponiente de Morelos pero creemos que, salvo las particularidades históricas de ésta, es un prototipo de muchas comunidades rurales de nuestro país, localizadas en territorios que no figuran entre los más importantes en términos de riqueza de recursos naturales, de biodiversidad 
o de prestación de servicios ambientales, ni siquiera de ubicación geográfica.

Estos lugares son, por decirlo de alguna manera, los territorios invisibles del país: no son objeto de política pública en materia ambiental, pues no figuran en la lista de zonas prioritarias de conservación; la presencia del Estado se materializa a través de programas de asistencia y alivio de la pobreza lo que, si bien por un lado ayuda momentáneamente, por el otro desmoviliza a la población en el corto y mediano plazos y la desaparece de la escena política estatal y nacional; finalmente, debido a la escasez de recursos, no son objeto de codicia por parte del gran capital, no están amenazados por él pues para éste no existen, no figuran en su mapa de intereses. Esto último podría ser una buena noticia; sin embargo no lo es pues, a pesar de su no visibilidad hacia fuera, esto no los ha protegido: ahí están, vulnerables, expuestos al deterioro.

El de Cuentepec es un caso analizado muy de cerca, pero como él podemos encontrar muchos ejemplos a lo largo y ancho del territorio nacional, los más, seguramente, en donde las condiciones de escasez social, política, económica y de recursos naturales se conjugan de tal forma que, no obstante que sus pobladores compartan valores y sentimientos de arraigo y pertenencia y los expresen a través de sus prácticas y sus instituciones, ello no garantiza en sí mismo ni la protección de sus recursos ni la existencia de proyectos de defensa de su territorio; éstos, desde nuestro punto de vista, requieren de un posicionamiento político distinto de las comunidades campesinas/indígenas en el contexto nacional, así como de reacomodos de fuerzas a nivel interno que les permitan crear y fortalecer capacidades locales.

\section{Bibliografía}

Aboites-Aguilar, Luis (1998), El agua de la nación. Una historia política de México (1888-1946), CIESAs, México.

Baland, Jean Mariet y Jean Philippe Platteau (1996), Halting Degradation of Natural Resources. Is there a Role for Rural Communities?, FAO, Roma.

Canabal, Beatriz, Gabriela Contreras y Arturo León (coords.) (2006), Diversidad rural: estrategias económicas y proce- 
sos culturales, Universidad Autónoma Metropolitana, Xochimilco-Plaza y Valdés, México.

Cimadamore, Alberto, Robyn Eversole y John-Andrew McNeish (2006), "Pueblos indígenas y pobreza. Una introducción a los enfoques multidisciplinarios", en A. Cimadamore et al. (coords.), Pueblos indigenas y pobreza. Enfoques multidisciplinarios, flacso, Buenos Aires, Argentina, pp. 17-37.

Díez, Domingo (1933), Bibliografía del estado de Morelos, Monografías Bibliográficas Mexicanas, Secretaría de Relaciones Exteriores, México.

Escobar, Arturo (1999a), “¿De quién es la naturaleza? La conservación de la biodiversidad y la ecología política de los movimientos sociales", en Arturo Escobar (comp.), El final del salvaje. Naturaleza, cultura y politica en la antropología contemporánea, CEREC-ICAN, Santa Fe de Bogotá.

Escobar, Arturo (1999b), "Comunidades negras de Colombia: en defensa de la biodiversidad, territorio y cultura", Biodiversidad, 22, REDES-AT, GRAIN, Grupo Semillas, Bogotá, Colombia, pp. 15-20

Giménez, Gilberto (2004), “Territorio, paisaje y apego socioterritorial”, en Gilberto Giménez (coord.), Regiones culturales-culturas regionales, Conaculta, Dirección de Vinculación Regional, México, pp. 29-50.

Gómez Garzón, Alfredo (2000), "Caracterización del medio físico de la cuenca del río Tembembe empleando sistemas de información geográfica (SIG CUENCAS)", documento de trabajo, Instituto Mexicano de Tecnología del Agua, Cuernavaca, México.

González-Ángeles, Livia (2005), “Milakuaj: etnografía de la ofrenda a los aires en Cuentepec, Morelos", tesis de licenciatura en antropología social, Universidad Autónoma del Estado de Morelos, Cuernavaca, México.

Landázuri, Gisela (1997), "Encuentros y desencuentros entre campesinos y asesores en el medio rural. El caso de Cuen- 
tepec, Morelos, México", ponencia presentada en el xx Congreso Internacional de la Asociación de Estudios Latinoamericanos, Guadalajara, México.

Lecoquierre, Bruno y Benjamin Steck (1999), "Pays emergents, parroisses recomposées”, Géographie et Cultures, 30, L'Harmattan, París, pp. 47-69.

Leff, Enrique (2005), "La geopolítica de la biodiversidad y el desarrollo sustentable. Economización del mundo, racionalidad ambiental y reapropiación social de la naturaleza", OSAL, Conflictos sociales y recursos naturales, año VI, 17, Clacso, Buenos Aires, pp. 263-274.

Paz-Salinas, María Fernanda (2005), La participación en áreas naturales protegidas. Actores e intereses en conflicto en el Corredor Biológico Chichinautzin, Mor., CRIM-UNAM, México.

Rosas, María (1997), Tepoztlán. Crónica de desacatos y resistencia, ERA, México.

Seoane, José (2005), "Movimientos sociales y recursos naturales en América Latina: resistencias al neoliberalismo, configuración de alternativas”, OSAL, Conflictos sociales y recursos naturales, año VI, 17, Clacso, Buenos Aires, pp. 93-108.

Toledo, Víctor (2000), La paz en Chiapas. Ecología, luchas indígenas y modernidad alternativa, Universidad Nacional Autónoma de México-Instituto de Biología, México.

Tizon, Philippe (1996), “Qu' est ce que le territoire?”, en Guy Di Méo (dir.), Les territoires du quotidien, L'Harmattan, París, pp. 17-34.

Recibido: 5 de junio de 2007. Aceptado: 21 de febrero de 2008. 
María Fernanda Paz Salinas. Es doctora en ciencias antropológicas por la Universidad Autónoma Metropolitana; fue becaria de la Fundación Rockefeller en el Programa de Estudios Avanzados en Medio Ambiente y Desarrollo Sustentable (LEAD) en El Colegio de México. Se desempeña como investigadora titular del Centro Regional de Investigaciones Multidisciplinarias de la UNAM y es miembro del Sistema Nacional de Investigadores (SNI), nivel I. Su trabajo de investigación gira en torno a la dimensión social del manejo, conservación y deterioro de los recursos naturales y en la actualidad trabaja en la línea de gobernanza ambiental local. Entre sus publicaciones más recientes destacan: La conservación en áreas naturales protegidas. Actores e intereses en conflicto en el Corredor Biológico Chichinautzin, Mor., CRIM-UNAM, Cuernavaca (2005); "Participación, cultura y política. Reflexiones sobre la acción colectiva en el Corredor Biológico Chichinautzin”, Mirada Antropológica, 4, Benemérita Universidad Autónoma de Puebla, México, pp. 9-24 (2005); en coautoría, Las áreas naturales protegidas del norte de Morelos, CRIM-UnAM, México (2006). 